\title{
O NEOLIBERALISMO E A ECONOMIA SOLIDÁRIA: UMA ANÁLISE DAS MOEDAS SOCIAIS NO ESTADO BRASILEIRO
}

\author{
NEOLIBERALISM AND THE SOLIDARY ECONOMY: AN ANALYSIS OF \\ SOCIAL CURRENCIES IN THE BRAZILIAN STATE
}

Área: Direito Econômico, Neoliberalismo.

\section{José Carlos Lourenço da Silva Junior ${ }^{1}$}

RESUMO: No Brasil, as políticas econômicas e sociais do projeto neoliberal, foram implementadas pelo governo de Fernando Collor de Mello e, posteriormente, intensificadas por Fernando Henrique Cardoso. Desde o início da década de 1990, a condução da política brasileira esteve em convergência com o ideário neoliberal. Houve uma fragilização dos sistemas sociais de proteção, o aumento do desemprego, a crescente exclusão social e a desigualdade na distribuição de renda no país. Nesse cenário, surgiu a economia solidária, um movimento social que tem por finalidade a mudança, para melhor, da sociedade, cujo desenvolvimento é embasado em valores de solidariedade, cooperação e direitos humanos. $\mathrm{Na}$ economia solidária, comunidades carentes, vítimas da inércia estatal, destituídas dos serviços essenciais e de um patamar mínimo civilizatório, criaram a moeda social, também denominada moeda solidária ou local, e os bancos comunitários, como forma de uma alternativa ao desenvolvimento econômico regional. Assim, o presente artigo analisa o importante papel da moeda social no cenário econômico nacional, demonstrando a sua atuação no desenvolvimento social e econômico de determinadas regiões precárias. Outrossim, faz uma reflexão acerca das moedas sociais à luz da Constituição Federal. O método de abordagem utilizado foi o dedutivo, combinado com a pesquisa bibliográfica.

PALAVRAS-CHAVE: Economia Solidária. Moeda Social. Neoliberalismo.

\begin{abstract}
In Brazil, the economic and social policies of the neoliberal project were implemented by the government of Fernando Collor de Mello and, subsequently, intensified by Fernando Henrique Cardoso. Since the beginning of the 1990s, the conduct of Brazilian politics has been in convergence with the neoliberal ideology. There was a weakening of
\end{abstract}

Mestre em Direito pela Universidade de Marília - SP 
social protection systems, an increase in unemployment, increasing social exclusion and inequality in income distribution in the country. In this scenario, solidarity economy emerged with the objective of improving the concept of solidarity, cooperation and human rights. Solidarity economy, poor communities, state dynamics, the dismemberment of essential services and minimum levels, the creation of social currency, also called solidarity or local currency, the bank of banks, as a way of an alternative to regional economic development. Thus, the present article analyzes the important role of the social currency in the national economic scenario, demonstrating its role in the social and economic development of certain precarious species. Moreover, it makes a reflection on social currencies in the light of the Federal Constitution. The method aplied was deductive, combined with bibliographic research.

KEYWORDS: Solidary Economy. Social Currency. Neoliberalism.

SUMÁRIO: Introdução. 1. A globalização e o neoliberalismo. 2. O desenvolvimento social e a ordem econômica constitucional. 3. A economia solidária e os bancos comunitários. 4. Moedas Sociais. Conclusão. Referências bibliográficas.

\section{Introdução}

A partir da década de 1970, o neoliberalismo ganhou relevância mundial. Trata-se de um movimento ideológico, modelo de orientação política e econômica, que constitui a expressão política da sociedade global e possui como característica a oposição ao Estado intervencionista e de Bem Estar Social.

No Brasil, observa-se que, no início da década de 1990, a condução da política esteve convergência com o ideário neoliberal, motivo pelo qual se adotaram diversas medidas para contenção dos gastos sociais.

As políticas econômicas e sociais do projeto neoliberal alavancaram as desigualdades. A pobreza e a dessemelhante distribuição de renda cresceram no país.

Assim, as comunidades brasileiras em situações precárias, vítimas do capitalismo e do neoliberalismo, pautado na busca incessante pelo lucro e na redução dos gastos sociais, passam utilizar a cooperação e a solidariedade como meio de efetivação de um patamar mínimo civilizatório.

Nesse contexto, a economia solidária apresenta-se como um movimento social que tem por finalidade a mudança, para melhor, da sociedade, cujo 
desenvolvimento é embasado em valores de solidariedade, cooperação, preservação do meio ambiente, direitos humanos, cidadania, democracia participativa e políticas públicas. O lucro deixa de ser a finalidade central, de modo que o núcleo passa ser o ser humano. A subordinação dá lugar à autogestão.

Surgem os bancos comunitários e a moeda social, também denominada moeda solidária ou local, inspirados na solidariedade.

A problemática que sobrevém é: as moedas sociais promovem o desenvolvimento econômico regional? Podem ser consideradas uma ameaça à moeda oficial?

A partir desses questionamentos, a presente pesquisa teve como objetivo examinar as denominadas moedas sociais digitais à luz dos preceitos constitucionais, verificando sua a compatibilidade com os objetivos fundamentais da República Federativa do Brasil e com a finalidade da ordem econômica.

Para tanto, no primeiro tópico desse artigo, abordamos o fenômeno da globalização e do neoliberalismo, destacando as políticas neoliberais no Brasil. No segundo, analisamos o desenvolvimento social e a ordem econômica à luz da Constituição Federal do Brasil. Já, no terceiro capítulo, tratamos da economia solidária no Brasil, discorrendo sobre os seus princípios e a existência de dispositivos legais que regulamentam o instituto. Outrossim, foram examinados os bancos comunitários e o fornecimento do microcrédito. No quarto tópico, abordamos acerca da economia solidária e dos bancos comunitários, em que foram avaliadas as moedas sociais. Dessa forma, analisamos a importância das moedas no desenvolvimento econômico e social das comunidades carentes situadas no Brasil e seus reflexos no cenário econômico pátrio.

Com isso, para este estudo, utilizamos o método de investigação qualitativo-bibliográfico, combinado com o método de abordagem dedutivo, tendo como foco inicial o disposto nos textos legais, bem como nos posicionamentos doutrinários que envolvem o tema, abrangendo livros, revistas, monografias, teses e artigos científicos.

\section{A globalização e o neoliberalismo}

A globalização abarca diversos fenômenos de ordem econômica, política, social e cultural, importando em uma configuração histórico-social abrangente. Anthony Giddens (2005, p. 51) aduz que: 
A globalização está a mudar a forma como o mundo nos apresenta e a maneira como olhamos para o mundo. Se adotarmos uma perspectiva global, tornamo-nos mais conscientes dos laços que nos unem às pessoas de outras sociedades. [...] A perspectiva global lembra-nos que os laços cada vez mais fortes que nos unem ao resto do mundo implicam que o que fazemos tem consequências na vida dos outros e que os problemas mundiais têm consequências para nós ${ }^{2}$.

Napoleão Miranda (2004, p. 88)³ suscita que a "globalização traduz-se, hoje, em uma crescente interdependência econômica das nações, materializada no fluxo do comércio, do capital, de pessoas e tecnologia entre elas".

Por sua vez, José Eduardo Faria (2008, p. 3) ensina que:

Globalização é um conceito aberto e multiforme que denota a sobreposição do mundial sobre o nacional e envolve problemas e processos relativos à abertura e liberalização comerciais, à integração funcional de atividades econômicas internacionalmente dispersas, à competição interestadual por capitais voláteis e ao advento de um sistema financeiro internacional sobre o qual os governos têm uma decrescente capacidade de comando e controle ${ }^{4}$.

E mais, em relação à globalização econômica, este mesmo autor suscita que (2008, p.3):

A globalização econômica relaciona-se com ideias de compreensão de tempo e espaço; de novas formas de comunicação (on-line, em tempo real); da abolição das fronteiras geográficas; da multiplicidade político-administrativa e da descentralização decisória. Conquanto impreciso, certos aspectos do conceito de globalização econômica são identificáveis na maioria das definições como por exemplo; a

2 GIDDENS, Anthony. As consequências da modernidade. (F. L. Machado, \& M. M Rocha, trad.). $4^{\mathrm{a}}$ ed. Oeiras: Celta Editora, 2005. p. 51.

3 MIRANDA, Napoleão. Globalização, Soberania Nacional e Direito Internacional. Revista CEJ, Brasília, n. 27, p. 86-94, 2004.

4 FARIA, José Eduardo. Sociologia Jurídica: direito e conjuntura. Série FGV Law. São Paulo: Saraiva, 2008. p. 3. 
internacionalização do setor bancário e desregulação dos mercados financeiros; a organização compreendida como rede em oposição ao modelo hierárquico; o desenvolvimento de bens e serviços de alto valor agregado; o aumento significativo na circulação de mercadorias, serviços, tecnologia, informação; a intensificação das relações sociais a nível mundial ${ }^{5}$.

O processo de mundialização do capital foi intensificado com a crise do capitalismo, no início da década de 70. Desde então, houve uma reestruturação do capitalismo, com mudanças na área econômica, política e social.

A globalização transformou os papéis desempenhados pelo Estado e a correlação de forças entre as nações. Reintroduziu a concepção de Estado mínimo do liberalismo clássico, porém, sob a denominação de neoliberalismo.

Implementado pelo governo de Margaret Thatcher (1979) e, posteriormente, por Ronald Reagan (1981), o projeto neoliberal de governo ganhou relevância no mundo, tornando-se parte integrante do processo de mundialização do capital.

De acordo com Perry Anderson (2003, p. 9-10):

[...]o neoliberalismo nasceu logo depois da II Guerra Mundial, na região da Europa e América do Norte, onde imperava o capitalismo. Foi uma reação teórica e política veemente contra o Estado Intervencionista e de Bem-Estar social.

Seu texto de origem é "O Caminho da Servidão", de Friedrich Hayek, escrito em 1944. Trata-se de um ataque apaixonado contra qualquer limitação dos mecanismos de mercado por parte do Estado, denunciadas como uma ameaça letal à liberdade econômica e política.

Três anos após escrever a mencionada obra, Friedrich Hayek, juntamente com outros pensadores neoliberais, em 1947, fundou a Sociedade de Mont Pèlerin, com a finalidade de combater o keynesianismo e o solidarismo reinantes e preparar as bases de outro tipo de capitalismo, duro e livre de regas para o futuro ${ }^{6}$.

FARIA, José Eduardo. Sociologia Jurídica: direito e conjuntura. Série FGV Law. São Paulo: Saraiva, 2008. p. 3.

6 ANDERSON, Perry. Balanço do Neoliberalismo. Rio de Janeiro: Editora Paz e Terra S/A, 
Para os neoliberais, as políticas keynesianas, inclusive a manutenção do Estado do Bem Estar Social, foram as vilãs da crise capitalista devido a terem gerado altos déficits e endividamentos públicos, limitando as ações comerciais e prejudicando a liberdade econômica.

Logo, é contra o estatismo, o planejamento, o protecionismo, o socialismo. Prega pela defesa da economia de mercado, da liberdade econômica concebida como fundamento da liberdade política, condição de prosperidade coletiva e individual.

Nesse diapasão, o neoliberalismo se caracteriza por uma ideologia voltada a implementar uma política estatal sem a interferência do Estado nas relações econômicas, buscando maior flexibilização na legislação trabalhista, redução da carga tributária, diminuição de gastos públicos com programas sociais, maior proteção à livre concorrência e privatização do setor público, deixando que as leis do livre mercado regulem a vida econômica da sociedade.

Em outras palavras, possui como proposta a eliminação de limites aos mercados e defende a livre iniciativa, a livre concorrência e a não intervenção do Estado na economia.

Tem por pressuposto desonerar o Estado de funções sociais e postula a liberdade, essencialmente, em relação ao comércio e à circulação de capital. As propostas neoliberais possuem como objetivo final a reanimação do capitalismo avançado mundial, restaurando altas taxas de crescimento estáveis, como existiam antes da crise dos anos 70 .

\subsection{O neoliberalismo no Brasil}

No Brasil, as políticas econômicas e sociais do projeto neoliberal foram implementadas pelo governo de Fernando Collor de Mello e se consolidou com a chegada de Fernando Henrique Cardoso à presidência.

No denominado Plano Collor, foram propostas a criação de uma nova moeda, a mudança de leis trabalhistas, abertura do mercado nacional (fundação do Mercosul) e a privatização de estatais.

No governo de Fernando Henrique Cardoso, o Estado passou de desenvolvimentista e grande investidor para regulador. Observa-se a criação de várias agências reguladoras, fundadas com o fito de ditar as regras para as novas empresas, que passaram a atuar no país.

2003.p. 9. 
Ademais, observam-se várias ideias neoliberais, tais como a privatização da telefonia estatal, a venda dos bancos estaduais, a privatização de empresas públicas, a redução dos funcionários públicos, por meio da aposentadoria antecipada ou demissão, a terceirização de trabalhadores e vários serviços do estado e a abertura do mercado nacional para empresas estrangeiras.

A inserção do Brasil no mercado mundial gerou um alto custo para a sociedade brasileira. A política econômica neoliberal trouxe como consequência, para a área social, uma crescente exclusão social demonstrada pela elevação da linha de pobreza de parte significativa da população brasileira, acentuando a desigual distribuição de renda no país.

Em que pese o Governo Lula ter recuperado o protagonismo do Estado como investidor, as consequências da política neoliberal no Brasil podem ser sentidas até hoje. Os setores que eram protegidos pelo poder público, como a educação, viram os investimentos diminuir e aumentar a participação do capital privado. Ademais, houve o aumento de concessões para empresas estrangeiras operarem no Brasil.

No Governo Temer, observaram-se diversos atos de caráter neoliberal. Foi proposta a PEC 55, que prevê a limitação constitucional dos gastos públicos por 20 anos, impossibilitando o funcionamento dos serviços públicos e da rede de proteção social. No mais, o governo se recusa a debater o injusto e ineficiente sistema tributário, que faz com que os pobres paguem a maior parte da sua renda em impostos, enquanto os ricos sejam desonerados e tenham a possibilidade de contribuir com menos de $30 \%$ de sua renda em tributos.

Nesse diapasão, o governo aprovou Lei n. ${ }^{0} 13.467 / 2017$, que alterou a Consolidação das Leis do Trabalho e reduziu ou flexibilizou diversos direitos, avançando na terceirização e garantindo o protagonismo da negociação direta entre empresários e trabalhadores.

A aproximação da política econômica brasileira atual com o neoliberalismo pode ser observada em relação aos bancos públicos e estatais; a título de exemplo, podemos citar o BNDES, que reduziu o volume de empréstimos, passando a financiar poucas áreas, e reduzindo seu papel social.

Atualmente, no governo Bolsonaro, com sua equipe econômica liderada pelo Sr. Paulo Guedes, houve a reforma da previdência que modificou o fator previdenciário e impôs a exigência de trabalhar por mais tempo, para se garantir um determinado acúmulo de recursos. Ademais, busca aprovar a reforma tributária. 
Portanto, no Brasil, é nítido que, nas últimas décadas, houve uma redução da intervenção do Estado na economia, bem como uma fragilização dos sistemas sociais de proteção, acarretando o aumento do desemprego, a crescente exclusão social e a desigualdade na distribuição de renda no país.

\section{O desenvolvimento social e a ordem econômica constitucional}

Nesse tópico, vamos analisar o desenvolvimento social e da ordem econômica, à luz da Constituição Federal do Brasil.

A Constituição Federal de 1988 constituiu o Estado Democrático de Direito (artigo $\left.1^{\circ}\right)^{7}$ e estabeleceu os objetivos fundamentais da República Federativa do Brasil:

Art. $3^{\circ}$ Constituem objetivos fundamentais da República Federativa do Brasil:

I - construir uma sociedade livre, justa e solidária;

II - garantir o desenvolvimento nacional;

III - erradicar a pobreza e a marginalização e reduzir as desigualdades sociais e regionais;

IV - promover o bem de todos, sem preconceitos de origem, raça, sexo, cor, idade e quaisquer outras formas de discriminação ${ }^{8}$.

A ordem econômica nacional, disciplinada pelo artigo 170, da Carta Magna, é fundada na valorização do trabalho humano e na livre iniciativa, tendo como finalidade assegurar, a todos, a existência digna, conforme os ditames da justiça social, observando, dentre vários princípios, o da redução das desigualdades regionais e sociais.

Sendo assim, à luz da Constituição Federal, a busca do desenvolvimento pelo Estado brasileiro, onde é presente o sistema capitalista de produção, deve observar e promover a solidariedade e a redução da desigualdade, a fim de proporcionar aos cidadãos uma existência digna.

Portanto, se de um lado a Constituição Federal de 88 enfatiza a livre

\footnotetext{
BRASIL. Constituição da República Federativa do Brasil, 1988. Disponível em <http://www. planalto.gov.br/ccivil_03/constituicao/constituicao.htm>. Acesso em: 28 jan. 2018.

8 BRASIL. Constituição da República Federativa do Brasil, 1988. Disponível em <http://www. planalto.gov.br/ccivil_03/constituicao/constituicao.htm>. Acesso em: 28 jan. 2018.
} 
concorrência, através do ideário neoliberal, por outro, busca o Estado de Bem Estar Social, eis que reforça a questão da redução das desigualdades regionais e sociais, bastante discutidas nos direitos e garantias fundamentais e, no atual momento, vivenciado pelo Brasil.

\section{A economia solidária e os bancos comunitários}

Conforme vimos, a Carta Magna de 1988 trouxe consigo uma característica neoliberal, qual seja, a livre concorrência. Contudo, em oposição às ideias neoliberais, foi imposto que a ordem econômica brasileira deve observar e promover a solidariedade e a redução da desigualdade.

É certo que o neoliberalismo acarretou a concentração de capital, culminando numa desigualdade crescente e na ausência de condições mínimas de dignidade em determinadas regiões brasileiras.

Assim, as comunidades brasileiras subdesenvolvidas ou nada desenvolvidas passaram a utilizar a cooperação e a solidariedade como meio de efetivação de um patamar mínimo civilizatório. Surge, então, o que se pode denominar de economia solidária.

Inerente à origem histórica da economia solidária, Paul Singer (2002, p. 24-25) aduz:

A economia solidária nasceu pouco depois do capitalismo industrial, como reação ao espantoso empobrecimento dos artesãos provocado pela difusão das máquinas e da organização fabril da produção. A Grã-Bretanha foi a pátria da Primeira Revolução Industrial, precedida pela expulsão em massa de camponeses dos domínios senhorial, que se transformaram no proletariado moderno. A exploração do trabalho nas fábricas não tinha limites legais e ameaçava a reprodução biológica do proletariado. As crianças começavam a trabalhar tão logo podiam ficar de pé, e as jornadas de trabalho eram tão longas que o debilitamento físico dos trabalhadores e sua elevada morbidade e mortalidade impediam que a produtividade do trabalho pudesse elevar. [...] A Revolução Francesa provocou um longo ciclo de guerras na Europa, que se encerrou apenas em 1815, após a vitória britânica sobre Napoleão em Waterloo. Logo a seguir a economia da Grã-Bretanha caiu em profunda depressão, 
Robert Owen apresentou uma proposta para auxiliar as vítimas da pobreza e do desemprego e restabelecer o crescimento da atividade econômica.[...] Em 1817, Owen apresentou um plano ao governo britânico para que os fundos de sustento dos pobres, cujo número estava se multiplicando, em vez de serem meramente distribuídos, fossem invertidos na compra de terras e construção de Aldeias Cooperativas, em cada uma das quais viveriam cerca de 1.200 pessoas trabalhando na terra e em indústria, produzindo assim a sua própria subsistência. Os excedentes de produção poderiam ser trocados entre as Aldeias. Com cálculos cuidadosos de quanto teria de ser investido em cada Aldeia, Owen tentava mostrar que haveria imensa economia de recursos, pois os pobres seriam reinseridos à produção ao invés de permanecerem desocupados ${ }^{9}$.

A Economia Solidária é um movimento social que tem por finalidade a mudança, para melhor, da sociedade, cujo desenvolvimento é embasado em valores de solidariedade, cooperação, preservação do meio ambiente, direitos humanos, cidadania, democracia participativa e políticas públicas.

Para melhor entendermos a Economia Solidária, devemos observá-la sobre três prismas. Na vertente econômica, verifica-se a existência da autogestão, ou seja, inexiste a relação bilateral do trabalho entre empregado e empregador; os integrantes do empreendimento, seja uma associação, cooperativa, ou simplesmente um grupo, são, ao mesmo tempo, trabalhadores e donos.

Trata-se de um modo de produção caracterizado pela igualdade. A produção é de posse coletiva dos que com ela trabalham, através dos empreendimentos de economia solidária, geridos pelos trabalhadores de forma coletiva e democrática.

No aspecto cultural, visa a transmutar o paradigma da competição para o da cooperação cumulada com a inteligência coletiva, livre e partilhada. Ademais, busca o consumo no comércio local de produtos locais, saudáveis, que respeitem o meio-ambiente e não beneficiem as grandes empresas, em especial, as multinacionais.

Sob a luz da política, é um movimento social que visa a transformar a sociedade através de um desenvolvimento efetivado pelas pessoas, a partir dos valores da solidariedade e cooperação, promovendo os direitos humanos.

\footnotetext{
9 SINGER, Paul. Introdução à Economia Solidária. $1^{\text {a }}$ ed: São Paulo: Editora Fundação Perse Abramo, 2002. p. 24-25.
} 
Portanto, possui um ideal diverso da competição, empregada no sistema capitalista de produção. Na economia solidária, o lucro deixa de ser a finalidade central, de modo que o núcleo passa ser o ser humano.

Patente, pois, que a economia solidária é uma reação às medidas de contenção dos gastos sociais, que acarretaram no aumento da pobreza.

\subsection{A economia solidária no Brasil}

No ano de 2001, foi realizado o I Fórum Social Mundial (I FSM), que contou com a participação de pessoas oriundas de 117 países, dentre eles o Brasil. Na oficina denominada "Economia Popular Solidária e Autogestão" foi discutida a auto-organização dos trabalhadores, políticas públicas e perspectivas econômicas e sociais de trabalho e renda.

A partir de então, foi constituído, no Brasil, o Grupo de Trabalho Brasileiro de Economia Solidária, que buscou a unidade na diversidade e construiu uma identidade para a "Economia Solidária", através da realização das plenárias e da elaboração dos Princípios da Economia Solidária. Apontava, especialmente, para a necessidade de combinar a ampliação regional com o investimento em empresas e empreendimentos de economia solidária.

No ano de 2002, o mencionado grupo elaborou uma Carta intitulada de "Economia Solidária como Estratégia Política de Desenvolvimento" para o, então, presidente da República, cujo conteúdo apresentava as diretrizes gerais da Economia Solidária e reivindicava a criação da Secretaria Nacional de Economia Solidária.

Um ano após, em 2003, foi constituída a Secretaria Nacional de Economia Solidária (SENAES) e criado o Fórum Brasileiro de Economia Solidária (FBES), cujo objetivo era promover um intercâmbio qualificado de interesses econômicos, sociais e políticos, numa perspectiva de superar práticas tradicionais de dependência.

Desde então, a Economia Solidária teve como desafio trabalhar com moeda social, além de gerir abastecimento, comercialização, promover rodadas de negócio, realizar feiras em todos os estados, fazer campanha de consumo consciente, comércio justo e solidário, constituir redes, cadeias produtivas, finanças solidárias, trabalhar no campo do marco legal, visando a criação de uma lei geral do cooperativismo e cooperativa de trabalho.

Após duas Conferências Nacionais de Economia Solidária, realizadas

102 • Themis Revista Jurídica • Ano $01 \cdot$ Volume $02 \cdot \mathrm{n}^{\circ} 02 \cdot$ Jul-Dez 2020 
nos anos de 2006 e 2010, respectivamente, em 2012 foi apresentado o Projeto de Lei 4.685/2012, que ficou conhecido como "PL da Economia Solidária". Posteriormente, no dia 31/10/2017, foi aprovada a redação final do mencionado projeto pela Comissão de Constituição e Justiça e de Cidadania (CCJC) e encaminhado para o Senado Federal.

O aludido projeto prevê a criação da Política Nacional da Economia Solidária, com linhas de crédito para capital de giro e para custeio e aquisição de bens móveis e imóveis. Também prevê ações de educação, formação e qualificação social e profissional, nos meios rural e urbano, para empreendimentos com perfil de economia solidária.

Observamos, pois, que a economia solidária ganhou destaque no Brasil, a partir de 2003, durante os governos de Luiz Inácio Lula da Silva e Dilma Rousseff. Tais governos foram marcados por políticas neokeynesianas, com o poder público direcionado à solução de históricos problemas de cunho social, em oposição às ideias neoliberais.

Ressaltamos que um dos grandes desafios da Economia Solidária é trabalhar com moeda social.

\subsection{O microcrédito e os bancos comunitários}

O Banco Central (BARONE, 2002) define o microcrédito como:

a concessão de empréstimos de baixo valor a pequenos empreendedores informais e microempresas sem acesso ao sistema financeiro tradicional, principalmente por não terem como oferecer garantias reais. É um crédito destinado a produção (capital de giro e investimento) e é concedido com o uso de metodologia específica ${ }^{10}$.

O sistema de garantia do microcrédito é diverso daquele concedido no sistema financeiro tradicional. Quando utilizadas, as garantias são àquelas mais próximas da condição socioeconômica do beneficiário como, por exemplo, onde grupo de pessoas é, ao mesmo tempo, tomador do crédito e avalista dos demais tomadores. É baseado numa relação de confiança.

O microcrédito é concedido de várias formas, seja por meio de ação do

10 Barone, Francisco Marcelo; Lima, Paulo Fernando; Dantas, Valdi; Rezende, Valéria. Introdução ao Microcrédito. Brasília: Conselho da Comunidade Solidária, 2002. p. 11. 
Poder Público, da sociedade civil ou da iniciativa privada. O poder público atua através de bancos oficiais de carteira especializada, como o Banco do Povo ou o Banco Comunitário do Brasil, mediante programas centralizados diretamente na figura do tomador do microcrédito. Existem também os programas públicos, que fomentam as instituições de microcrédito da sociedade civil e da iniciativa privada, como o Programa de Crédito Produtivo Popular do BNDS.

No prisma da sociedade civil ou da iniciativa privada, o microcrédito pode ser distribuído por organizações não governamentais, qualificadas como Organização da Sociedade Civil de Interesse Público (OSCIP), desde que não possua finalidade lucrativa.

Ressaltamos que o microcrédito também pode ser fornecido pela iniciativa com objetivo de lucro, desde que seja uma Sociedade de Crédito ao Microempreendedor (SCM), disciplinada pela Lei 10.194/01, mediante a autorização de funcionamento e sob a supervisão do Banco Central do Brasil. Outrossim, pode ocorrer do microcrédito ser oferecido por uma instituição pertencente ao Sistema Financeiro Nacional.

Portanto, o microcrédito é um mecanismo de democratizar o acesso ao crédito. É uma ferramenta de combate à pobreza e de melhoria da qualidade de vida.

Por sua vez, em relação aos Bancos Comunitários, temos que:

Bancos Comunitários são serviços financeiros solidários, em rede, de natureza associativa e comunitária, voltados para a geração de trabalho e renda na perspectiva de reorganização das economias locais, tendo por base os princípios da Economia Solidária. Seu objetivo é promover o desenvolvimento de territórios de baixa renda, através do fomento à criação de redes locais de produção e consumo. Baseia-se no apoio às iniciativas da economia popular e solidária em seus diversos âmbitos, como: de pequenos empreendimentos produtivos, de prestação de serviços, de apoio à comercialização e o vasto campo das pequenas economias populares ${ }^{11}$.

O modelo clássico do Banco Comunitário é aquele que advém de uma comunidade insatisfeita com suas condições sociais, econômicas e financeiras,

\footnotetext{
11 Instituto Palmas. O que é um banco comunitário. Disponível em: http://www.institutobancopalmas.org/o-que-e-um-banco-comunitario/. Acesso em: 28 jan. 2018.
} 
que inclusive possui a sua moeda social.

Nesse caso, a própria comunidade é a proprietária do banco comunitário. Este, por sua vez, é gerido por uma organização (da sociedade civil). Além da entidade gestora, é necessário que exista, ou que seja formado, um conselho local responsável pela controladoria social do banco. Na composição do mencionado conselho, estão os representantes de diversas organizações, associações, instituições da sociedade civil, formais ou informais. Também pode ser composto por gestores públicos.

Digno de nota informar que existem os Bancos Comunitários, os quais são formados com auxílio ou diretamente pelo poder político, geralmente articulado com as políticas de redistribuição de renda, como é o caso do Banco Cocais, que possui a moeda social denominada Cocal, e o Banco Popular de Maricá, cuja moeda social recebe o nome do Mumbucá, ambos criados por leis municipais. Contudo, nosso foco será o modelo tradicional, em que própria comunidade é a proprietária do banco comunitário.

Até o presente momento, não existe no Brasil uma lei própria em vigência que disciplina os bancos comunitários e as finanças solidárias. Nesta ausência, os bancos comunitários devem observar normas esparsas no ordenamento jurídico pátrio.

Para operar o crédito produtivo, com uma carteira própria, a entidade gestora do banco comunitário deve possuir um título de OSCIP de Microcrédito, ou estar conveniada com uma entidade que já possua esse título, nos termos das Leis 9.970/1999 e 11.110/2005.

Ressaltamos que os bancos comunitários que não tenham título de OSCIP, só devem operar crédito produtivo com juros no valor máximo de $1 \%$ ao mês, conforme Decreto n. ${ }^{\circ}$ 22.626/1933 (Lei da Usura). Na hipótese de o banco comunitário operar crédito produtivo, em parceria com os bancos públicos, deverão seguir as normas que este estabelecer. Outrossim, não deverão ser cobrados juros para empréstimo em moeda social.

No tocante aos microsseguros, o banco comunitário deverá possuir parceria com uma seguradora e uma corretora autorizada, eis que somente poderá ser comercializado caso haja um registro na SUSEP.

O banco comunitário é autônomo e se organiza por autogestão, por tal motivo deve ter como entidade gestora uma organização da sociedade civil, que responde legalmente pelos seus atos. Ressaltamos que não há banco comunitário que seja filial de outro. 
Portanto, extraímos que os bancos comunitários são serviços financeiros solidários, em rede, de natureza associativa e comunitária, com a especial finalidade de reorganizar a economia local nos territórios de baixa renda, fomentando a criação de redes locais de produção e consumo, gerando, assim postos de trabalho e renda. Busca dar apoio às iniciativas da economia popular e solidária. Utiliza-se de moedas sociais. Portanto, é um instrumento de promoção do desenvolvimento econômico responsável pela execução dos serviços financeiros da comunidade.

\section{Moedas Sociais}

Conforme vimos, um dos desafios da Economia Solidária foi a utilização das moedas sociais. Nesse tópico, vamos analisar as moedas sociais no cenário econômico brasileiro. Para tanto, trataremos da moeda de cunho forçado (o real), demonstraremos a existência das moedas paralelas, para, então, discutirmos sobre a moeda social e o seu posicionamento no cenário econômico brasileiro.

A moeda é mais que uma imposição estatal, trata-se de um fenômeno social.

O reconhecimento pelos integrantes de uma comunidade faz com que um determinado instrumento ou objeto tenha valor e seja amplamente aceito para intermediar as trocas e as demais transações.

A denominada moeda nacional é aquela de cunho forçado, cujo monopólio da emissão pertence ao Estado, através de seus Bancos Centrais. Somente esta é detentora de poder para saldar dívidas, de forma válida e eficaz, ou seja, é capaz de adimplir as obrigações contratuais.

Trata-se de uma criação do direito. O poder do Estado de decidir qual será a moeda oficial do país e o seu reconhecimento, perante os demais Estados, é um aspecto de soberania nacional.

Contudo, o monopólio de emissão das moedas pelo Estado, através do banco central, deu origem aos movimentos os sociais que defendiam a implantação e circulação de moedas paralelas. Estes movimentos sociais eram caracterizados por um grupo de pessoas descontentes com a qualidade ou inexistência de serviços prestados pelo Estado, com a crise econômica, política e social. Tỉnham como premissa a criação de novos instrumentos de troca, os quais possibilitem as transações econômicas simples e um desenvolvimento econômico local. Nesse panorama, foram criadas as moedas paralelas.

As moedas paralelas são aqueles instrumentos de troca, utilizado 
em um contexto que já existe uma moeda oficial/legal, comumente aceito por determinado grupo de pessoal que, por sua vez, reconhecem nesse instrumento o caráter de moeda. No entanto, carecem de reconhecimento jurídico por parte do Estado. Apenas são utilizadas e reconhecidas, como meio circulante, por aqueles que as empregam.

Portanto, concluímos que tudo aquilo que não está investido de autoridade necessária para poder ser reconhecido como moeda oficial, tornase "instrumento alternativo de pagamento", sendo irrelevante para o direito em termos monetários, sem poder liberatório e cujo tratamento se dará pela via do direito privado contratual.

\subsection{As moedas sociais, solidárias ou locais}

A moeda social, também denominada moeda solidária ou local, é um instrumento paralelo à moeda oficial (no caso, o real). Seu objetivo é fazer com o que o dinheiro circule e gere riqueza em determinada comunidade, haja vista que a moeda social é aceita somente naquela região. Ao invés de empregar o dinheiro comprando de grandes marcas, com a moeda social há um incremento da economia local ao incentivar as pessoas a consumirem dos pequenos comerciantes e prestadores de serviço locais.

As moedas sociais são uma realidade em diversas comunidades no Brasil. Conforme vimos, estão ligadas aos Bancos Comunitários. É comum a política de cada banco oferecer descontos em produtos para quem efetua a compra com a moeda local. As medidas são sempre no sentido de incentivar que os recursos permaneçam na própria comunidade e mantenham a economia local aquecida.

A primeira moeda social do Brasil foi criada pelo Banco Comunitário Palmas (Palmas Card), visando ao estímulo ao consumo local. O banco antecipava crédito aos moradores, vinculado a um cartão feito de papel (Palmas Card) que só era aceito dentro do Conjunto Palmeiras, com a finalidade de incentivar as compras no comércio do próprio bairro.

O cartão possuía frente e verso. O verso era reservado ao preenchimento dos campos destinados a anotar o valor dos gastos realizados pelo seu proprietário. Quem anotava eram os comerciantes que iriam receber o crédito. O anverso tinha a logomarca do Banco Palmas e a discriminação do valor total do crédito concedido ao usuário do cartão. Tal cartão era elaborado de forma manual, através do programa Word, em um computador. 
Incumbia ao consumidor se registrar no banco para ganhar o seu cartão. Com a posse deste, o consumidor já estava apto a consumir localmente. Cada comerciante anotava no verso do cartão o valor total da compra realizada, observando o limite de crédito concedido pelo banco ao cliente. No final do mês, o comerciante se dirigia ao banco, com as faturas das vendas realizadas e o repasse em dinheiro era feito a ele.

Atualmente, as moedas possuem outras características físicas. Devem possui, no anverso, o nome e endereço da entidade gestora do banco e, no verso, deve ter um texto explicativo de que se trata de um bônus destinado a promover o desenvolvimento local e de uso exclusivo para troca de produtos e serviços na comunidade. Não há mais campos para anotações. Cada cédula possui o seu valor específico que será aceito pelo comerciante.

Para serem emitidas pelos bancos comunitários, as cédulas devem ser lastreadas e indexadas em moeda nacional corrente. Além de possuir o câmbio para a moeda nacional corrente e vice-versa, também deve ter a sua circulação restrita ao território de atuação do banco comunitário e ser de livre aceitação pelos moradores e comércio local.

No Brasil, ocorre a circulação de diversas moedas sociais, tais como a denominada "Gostoso", em São Miguel do Gostoso-RN, a "Maracanã", em Maracanaú-CE, a "Terra”, em Vila Velha-ES, a "Capivari”, em Silva Jardim-RJ, a "Trilho", em Simões Filho-BA, a "Cajueiro", em Cajueiro da Praia-PB, dentre outras.

\subsection{A moeda social na economia brasileira}

A moeda social, considerada, hodiernamente, um instrumento complementar à moeda oficial, é uma alternativa ao desenvolvimento econômico e social de comunidades carentes brasileiras, onde a inércia estatal deixou de promover os serviços essenciais e de cunho social.

Possui como supedâneo o fundamento constitucional expresso no artigo $3^{\mathrm{o}}{ }^{12}$ que visa construir uma sociedade livre, justa e solidária, bem como garantir o desenvolvimento nacional, erradicar a pobreza e a marginalização, além de reduzir as desigualdades sociais e regionais.

A moeda social proporciona a eficiência econômica, tendo em vista que 12 BRASIL. Constituição da República Federativa do Brasil, 1988. Disponível em <http://www.
planalto.gov.br/ccivil_03/constituicao/constituicao.htm>. Acesso em: 28 jan. 2018. 
elimina o tempo gasto para a realização de trocas diretas de bens e serviços, também considerado custo de transação, na economia agregada, permitindo o desenvolvimento de processos indiretos de pagamentos, conhecidos como trocas indiretas. Ele também dinamiza a atividade econômica do comércio local, através do financiamento de pequenas atividades econômicas que são diretamente responsáveis pela geração de riqueza e renda em nível local, para microempreendedores individuais, microempresas e trabalhadores autônomos.

Ademais, oferece uma proteção do meio ambiente, da cultura e de outros valores característicos dos espaços locais contra os efeitos perversos da globalização no processo de desenvolvimento. Com as moedas sociais, há uma transformação do próprio sistema de trocas, onde se observa uma priorização dos interesses da eficiência econômica em detrimento das necessidades de justiça social.

E ainda as moedas sociais proporcionam uma integração social, haja vista que fomentam a circulação local e recíproca de riquezas, organizada sobre um sistema de confiança existente em determinada comunidade, bem como amenizam as consequências advindas da escassez do dinheiro oficial (real) em determinadas comunidades ou regiões.

Em relação ao cenário econômico nacional, observamos que, em condições normais, a moeda social não ameaça os sistemas de pagamentos nacionais, nem coloca em risco a estabilidade do sistema financeiro, bem como não afeta o poder dos bancos centrais de controlar a quantidade de moeda e de crédito.

Podemos dizer que as moedas sociais constituem um evento relativamente inexpressivo dentro do sistema monetário de um país, mas de grande importância para o desenvolvimento de comunidades locais, contribuindo para a redução das desigualdades e a erradicação da pobreza no Brasil.

Oportuno salientarmos que, na eventualidade de a moeda social representar um risco à moeda oficial, o Estado, certamente, irá eliminá-la ou proibir o seu uso.

\section{Conclusão}

No Brasil, a globalização e a adoção de políticas neoliberais contribuíram para a fragilização dos sistemas sociais de proteção, o aumento do desemprego, a crescente exclusão social e a majoração da desigualdade na distribuição de renda. 
A Carta Magna de 1988, em que pese ter adotado a livre concorrência, em sentido neoliberal, estabeleceu, por outro lado, como objetivos fundamentais da República Federativa do Brasil, a construção de uma sociedade livre, justa e solidária, bem como a erradicação da pobreza, da marginalização e a redução das desigualdades sociais e regionais, impondo, portanto, um Estado de bem-estar social.

Observamos que a solidariedade foi recepcionada pelo mundo jurídico, pois se trata de um princípio aplicado a todos os ramos do direito. Está prevista no ordenamento jurídico pátrio, de forma expressa, no artigo $3^{\circ}$, I, da Constituição Federal. Por sua vez, a ordem econômica nacional (artigo 170, da CF), fundada na valorização do trabalho humano e na livre iniciativa, roga pela existência digna, conforme os ditames da justiça social.

Sendo assim, extraímos que a busca do desenvolvimento pelo Estado brasileiro, em que é presente o sistema capitalista de produção, deve observar e promover a solidariedade e a redução da desigualdade, a fim de proporcionar aos cidadãos uma existência digna.

Nesse contexto, surge a Economia Solidária, um movimento social que tem por finalidade a mudança, para melhor, da sociedade, cujo desenvolvimento é embasado em valores de solidariedade, cooperação, preservação do meio ambiente, direitos humanos, cidadania, democracia participativa e políticas públicas. O lucro deixa de ser a finalidade central e o núcleo passa ser o ser humano. A subordinação dá lugar a autogestão.

Comunidades carentes, vítimas da inércia estatal, destituídas dos serviços essenciais e de um patamar mínimo civilizatório, criaram a moeda social, também denominada de moeda solidária ou local, e os bancos comunitários, como (...) uma alternativa ao desenvolvimento econômico regional.

A moeda social é um instrumento complementar à moeda oficial; um mecanismo de políticas públicas de finanças solidárias, desenvolvida para amenizar as consequências advindas da escassez do dinheiro oficial (real) em determinadas comunidades ou regiões.

Os Bancos Comunitários, detentores de sua moeda social própria, disponibilizam aos cidadãos da região um microcrédito, como mecanismo de desenvolvimento e erradicação da pobreza. Assim, proporcionam uma integração social, haja vista que fomentam a circulação local e recíproca de riquezas, organizada sobre um sistema de confiança existente em determinada comunidade.

A moeda social é vista como legítima a partir dos objetivos fundamentais 
instituídos na Constituição Federal, em seu art. $3^{\circ}$, pois o seu objetivo é garantir o desenvolvimento de uma determinada região, erradicando a pobreza e a marginalização. Visa a construir uma sociedade livre, justa e solidária, reduzindo as desigualdades sociais e regionais. É um mecanismo de solidariedade.

No cenário econômico nacional, é possível afirmarmos que a moeda social não ameaça os sistemas de pagamentos, não coloca em risco a estabilidade do sistema financeiro, sequer afeta o poder dos bancos centrais de controlar a quantidade de moeda e de crédito.

Portanto, concluímos que moedas sociais constituem um evento relativamente inexpressivo dentro do sistema monetário de um país, mas de grande importância para o desenvolvimento de comunidades locais, contribuindo para redução das desigualdades e a erradicação da pobreza no Brasil.

\section{Referências bibliográficas}

ANDERSON, Perry. Balanço do Neoliberalismo. Rio de Janeiro: Editora Paz e Terra S/A, 2003. p. 9.

BARONE, Francisco Marcelo et al. Introdução ao Microcrédito. Brasília: Conselho da Comunidade Solidária, 2002. p. 11.

BRASIL. Constituição da República Federativa do Brasil, 1988. Disponível em $<$ http://www.planalto.gov.br/ccivil_03/constituicao/constituicao.htm>. Acesso em: 25 jul. 2017.

. Lei $n^{\circ} 12.865$, de 9 de outubro de 2013. Autoriza o pagamento de subvenção econômica aos produtores da safra 2011/2012 de cana-de-açúcar e de etanol que especifica e o financiamento da renovação e implantação de canaviais com equalização da taxa de juros; dispõe sobre os arranjos de pagamento e as instituições de pagamento integrantes do Sistema de Pagamentos Brasileiro (SPB); autoriza a União a emitir, sob a forma de colocação direta, em favor da Conta de Desenvolvimento Energético (CDE), títulos da dívida pública mobiliária federal; estabelece novas condições para as operações de crédito rural oriundas de, ou contratadas com, recursos do Fundo Constitucional de Financiamento do Nordeste (FNE); altera os prazos previstos nas Leis no 11.941, de 27 de maio de 2009, e no 12.249, de 11 de junho de 2010; autoriza a União 
a contratar o Banco do Brasil S.A. ou suas subsidiárias para atuar na gestão de recursos, obras e serviços de engenharia relacionados ao desenvolvimento de projetos, modernização, ampliação, construção ou reforma da rede integrada e especializada para atendimento da mulher em situação de violência; disciplina o documento digital no Sistema Financeiro Nacional; disciplina a transferência, no caso de falecimento, do direito de utilização privada de área pública por equipamentos urbanos do tipo quiosque, trailer, feira e banca de venda de jornais e de revistas; altera a incidência da Contribuição para o PIS/Pasep e da Cofins na cadeia de produção e comercialização da soja e de seus subprodutos; altera as Leis nos 12.666, de 14 de junho de 2012, 5.991, de 17 de dezembro de 1973, 11.508, de 20 de julho de 2007, 9.503, de 23 de setembro de 1997, 9.069, de 29 de junho de 1995, 10.865, de 30 de abril de 2004, 12.587, de 3 de janeiro de 2012, 10.826, de 22 de dezembro de 2003, 10.925, de 23 de julho de 2004, 12.350, de 20 de dezembro de 2010, 4.870, de 1o de dezembro de 1965 e 11.196 , de 21 de novembro de 2005, e o Decreto no 70.235, de 6 de março de 1972; revoga dispositivos das Leis nos 10.865, de 30 de abril de 2004, 10.925, de 23 de julho de 2004, 12.546, de 14 de dezembro de 2011, e 4.870, de 1o de dezembro de 1965; e dá outras providências. Disponível em: <http://www.planalto.gov.br/ ccivil_03/_ato2011-2014/2013/lei/112865.htm>. Acesso em: 28 jan. 2018.

FARIA, José Eduardo. Sociologia Jurídica: direito e conjuntura. Série FGV Law. São Paulo: Saraiva, 2008. p. 3.

GIDDENS, Anthony. As consequências da modernidade. (F. L. Machado, \& M. M Rocha, trad.). $4^{\mathrm{a}}$ ed. Oeiras: Celta Editora, 2005. p. 51.

INSTITUTO PALMAS. O que é um banco comunitário. Disponível em: http:// www.institutobancopalmas.org/o-que-e-um-banco-comunitario/. Acesso em: 28 jan. 2018.

MIRANDA, Napoleão. Globalização, Soberania Nacional e Direito Internacional. Revista CEJ, Brasília, n. 27, p. 86-94, 2004.

SINGER, Paul. Introdução à Economia Solidária. $1^{\mathrm{a}}$ ed: São Paulo: Editora Fundação Perse Abramo, 2002. p. 24-25. 